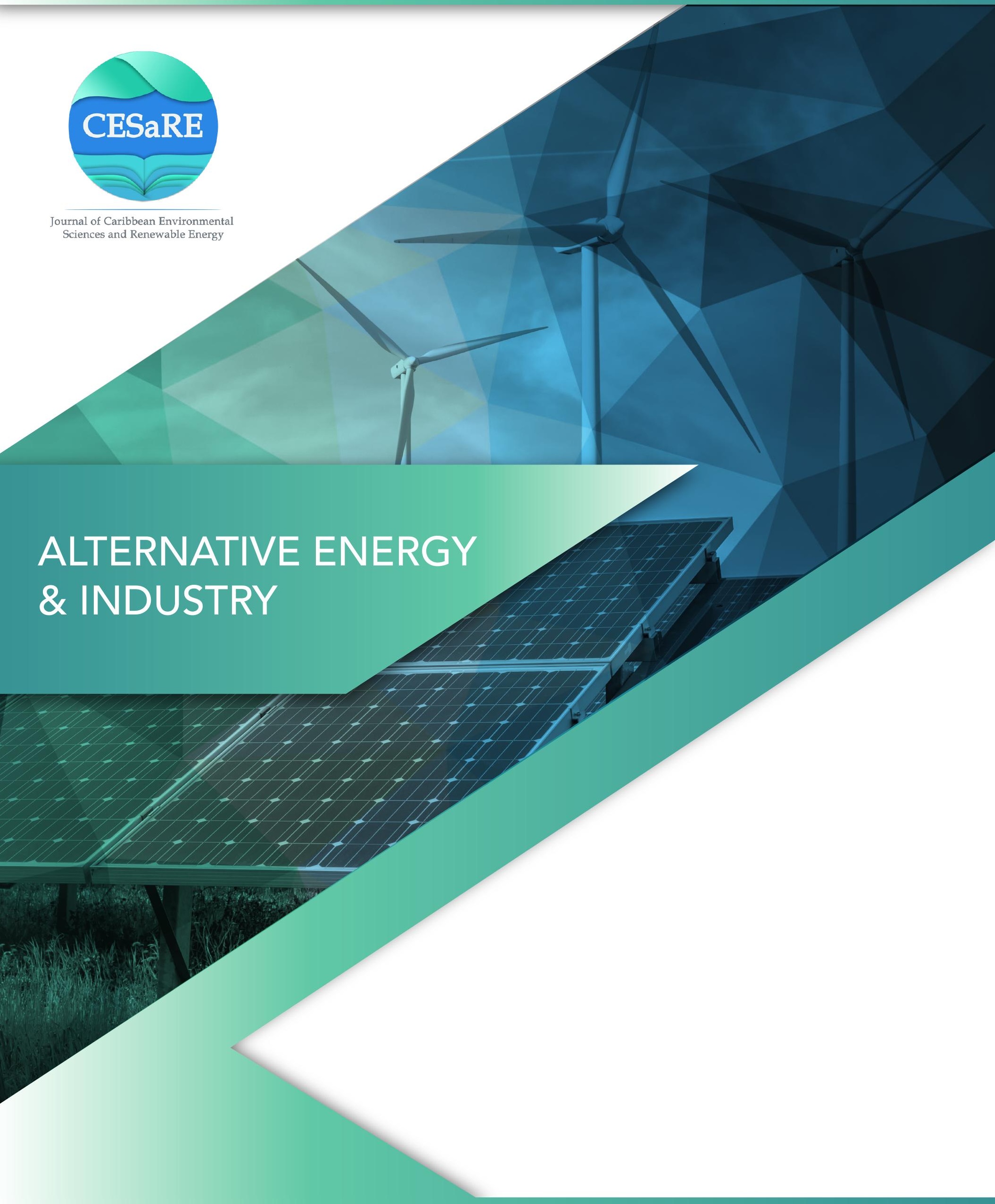




\title{
RENEWABLE ENERGY: A Caribbean Crossroad
}

\author{
Author: Dr. Randy Koon Koon \\ University of the West Indies, Department of Physics, Mona Campus
}

\section{INTRODUCTION}

\section{The Caribbean Community (CARICOM)}

The Caribbean Community consists of a total population of just over seventeen million people and fifteen members of state, from Antigua and Bermuda, to Suriname and Trinidad and Tobago, encompassing geographic, cultural and economic diversity. Energy consumption and generation are the two pivotal challenges that have continuously confronted Caribbean nations. All fifteen CARICOM nations rely on the importation of fossil fuels, some more than others, and as such, all are susceptible to the volatile nature associated with oil prices. The cost of domestic retail electricity rates in the Caribbean islands is averaged at USD $\$ 0.35 / \mathrm{kWh}^{[1]}$ Once more, the rate of retail electricity price depends heavily on the extent of fossil fuel importation. Collectively, the CARICOM members total roughly USD $\$ 4.9$ billion for annual fossil fuel import costs.

Why transition to carbon-free and climate-sensitive nations?

There exists an overwhelming necessity for the transition away from fossil fuels and towards the realm of sustainable energy. The unrelenting pursuit of energy security has yielded a regional Energy-Policy in 2013. ${ }^{[2]}$ Through climate-compatible development, efficient utilization of renewable resources, and carbon dioxide emission targets, CARICOM has charted an era of true regional change. Hence climate change discussions are frequently positioned close to the area of renewable energy. The physical and observable effects of climate change have continued to affect nations globally and the Caribbean nations are particularly vulnerable. In the context of global carbon dioxide emissions, CARICOM nations account for quite a small proportion (0.24\% in 2012). Among the fifteen CARICOM member states, the twin island republic of Trinidad and Tobago considerably leads the carbon dioxide emissions from energy consumption. In addition, Trinidad and Tobago is also the third highest nation per capita of carbon dioxide levels globally ${ }^{[3]}$. The Caribbean has experienced warmer-than-average temperature conditions during 2016, and Trinidad and Tobago clearly exhibited record-breaking temperatures.

In 2016, Trinidad and Tobago recorded it second-warmest $\left(28.4^{\circ} \mathrm{C}\right)$ year, with its second-highest annual mean maximum temperature of $31.7^{\circ} \mathrm{C}$. Furthermore, monthly mean temperatures (July; $33.4^{\circ} \mathrm{C}$, October; $34.3^{\circ} \mathrm{C}$ ) and daily extreme temperatures (April; $36.3^{\circ} \mathrm{C}$, October; $36.2^{\circ} \mathrm{C}$ ) were also recorded ${ }^{[4]}$. The tropical Caribbean islands are among the vulnerable areas to experience the immediate and enhanced effects of climate change. Low latitudes and exposure to the fertile expanse of the Atlantic sea, generates not only increased frequency of hurricanes visiting the Caribbean but also higher categories of these furious climatic occurrences. Hence Caribbean nations must collectively combat the intimate relation of increased carbon emissions and its link to worsening climatic conditions, through an increased number of installed larger scale renewable energy systems to produce carbon-free form of energy. The incorporation of renewables into the energy mix can inevitably tilt the scale and yield favorable benefits on both an economic and environmental scale. 
What is sustainable energy?

Renewable energy (RE) is a clean form of energy that derives its power through a resource that is naturally replenished on a human timescale, and the by-products are inherently carbon-free. The extent to which energy is captured to maximize the power output (useful work) of a resource while minimizing the loss of power through heat or other forms can be termed as energy efficiency. It is the combination of both RE and energy efficiency that breeds life to sustainable energy.

The major forms of renewable energy across the Caribbean

The major forms of renewable energy across the Caribbean are Solar, Wind, Hydropower and Geothermal energy, with hydropower notably leading the charge globally and regionally. Belize and Jamaica collectively account for 126.1 MW of hydropower potential, holding an $82 \%$ utilization overall. There exists a maximum of 800.4 MW of untapped wind energy potential throughout the Caribbean, however, except for Jamaica that leads the way with a maximum potential of 1,313 MW and having 34\% utilization. ${ }^{[6]}$ The immense untapped power beneath the islands of Dominica, Grenada, and St. Kitts all contribute towards 3,770 MW of potential geothermal energy. Furthermore, this collective power potential is approximately 28 times more than their power capacity requirement as of 2015, therefore such islands can become energy exporters. And finally, solar power stands at a maximum power potential of 2525.9 MW, however, only around $1.2 \%$ of the solar resource has been utilized. Jamaica leads the solar power frontier with the Content Solar farm, a 20 MW solar park that is one of the largest of such a facility within the Caribbean. ${ }^{[5]}$

The mutual challenges encountered by all Caribbean nations are dwarfed by the abundance of unexploited renewable energy resources. If such an encouraging possibility was to be fulfilled, it will undoubtedly position the Caribbean as one of the many beacons of change combatting global efforts towards climate change, while promoting sustainable energy development and securing the economic and societal needs of their nations.

\section{Implications - Renewable energy hindrances}

Although these actions previously mentioned for the introduction of renewables are highly commendable, there still exists challenges at hand for such a transition. Notable reasons for such a tentative nature exhibited by many nations arise from, uncertainty in the energy prices (as such projections are coherent in regard to the oil and gas industry prices), a lack of energy diversification and review of business models, and replacement of decommissioned baseload systems. Furthermore, technical (isolated grid networks, incapable to produce present and future energy demands), socioeconomic, and environmental challenges act as the major hindrances for the CARICOM region. ${ }^{[2]}$

\section{Looking ahead to the future}

Most Caribbean nations lack the size to self-sufficiently challenge for large-scale renewable energy projects that attempt to attract volume-oriented international financial markets. Hence the allure to establish innovative financial opportunities on a regional scale can provide an alternative to enhance the development of renewable energy projects of such scales. However, as previously mentioned, recognizable progress has been made throughout the Caribbean nations to foster and integrate renewables into the energy mix. Furthermore, CARICOM's sustainable energy programs have been introduced through the Caribbean Centre for Renewable Energy and Energy Efficiency (CCREE) organization created on February 2015. ${ }^{[2]}$ The realization of renewable energy technology and applications have been ongoing across 
Caribbean nations through academia, private sector organizations and governmental programs. The continued efforts at a regional, governmental, and societal level plays a crucial role to assist nations, to meet established renewable energy targets. No longer on the periphery, renewable energy, through efforts of dissemination, application, and integration, is now distinguishably carved into the energy mix of Caribbean nations.

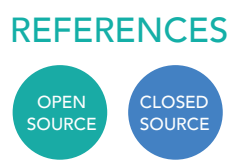

To access any closed-source references used in this article, please contact the author for an original manuscript.

1. Energy Chamber. 2017. "Understanding the Electricity Subsidy in T\&T" Accessed on August 10, 2018. http://energynow.tt/blog/understand ing-the-electricity-subsidy-in-tt

2. Ochs, A., M., Konnold, K., Auth, E., Mosolino and P., Killen. 2015. Caribbe an Sustainable Energy Roadmap and Strategy (C-SERMS): Baseline Report \& Assessment. Washington, DC: Worldwatch Institute.

3. The World Bank, IBRD-IDA. 2018. "Carbon dioxide emissions (metric tons per capita)." Accessed June 27, 2018. https://data.worldbank.org/indica tor/EN.ATM.CO2E.PC.

4. Blunden, J., and D. S. Arndt, Eds., 2017. State of the Caribbean in 2016. Bull. Amer. Meteor. Soc., 98 (8), Si-S277, doi:10.11175/2017BAMSStateoft heClimate. I.

5. Renewables Now. 2015. "Content Solar starts work on 20-MW project in Jamaica." Accessed June 27, 2018. https://renewablesnow.com/news/ content-solar-starts-work-on-20-mw-project-in-jamaica-483843/

6. World Watch Institute: Vision for a Sustainable World. 2015. "Caribbean Sustainable Energy Roadmap and Strategy (C-SERMS), CARICOM Member Country Energy Profiles." Accessed June 27, 2018. http://ww w.worldwatch.org/sustainable-energy-roadmaps. 